\title{
Genotoxicidad en linfocitos humanos inducida por extractos de durazno, Prunus persica cultivados en Pamplonita Norte de Santander.
}

\author{
Genotoxicity in human lymphocytes induced by extracts of peach, \\ Prunus persica grown in Pamplonita Norte de Santander.
}

Recepción: 31 de octubre de 2016

Luis Fabián Yañez ${ }^{a}$

Alfonso Quijano Parra ${ }^{b}$

Iván Meléndez Gélvez ${ }^{\mathrm{c}^{*}}$

Aceptación: 30 de diciembre de 2016

\begin{abstract}
The peach fruit species is the second most important after the apple tree in the Rosaceae. Pesticides are considered as one of the main factors of environmental pollution; They are widely used to improve food production in agriculture and to control pests and disease vectors; many have been classified as carcinogens, because they induce damage to genetic material. This paper was determined genotoxicity produced by extracts of peach (Prunus pérsica (L.)Batsch) grown in the municipality of Pamplonita, Norte de Santander. The comet assay was used to evaluate the genotoxic activity. For pesticide detection, gas chromatography $(\mu E C D)$ was used. The results indicate that the peach extract induces DNA damage in human lymphocytes, which varies according to the dose of the extract; by chromatography, pesticides like endosulfan II and Beta BHC, which belong to the family of organochlorines were detected. Since the peach is an export product and high consumption in our region, the intake of this could become a risk factor for the population.
\end{abstract}

Keywords. Peach, genotoxicity, comet assay, pesticide

\section{Resumen}

El durazno es la segunda especie frutal de mayor importancia después del manzano, en las rosáceas. Los pesticidas son considerados como uno de los principales factores de contaminación del medio ambiente; como es conocido son ampliamente utilizados para mejorar la producción de alimentos en la agricultura y para el control de plagas y vectores de enfermedades; muchos han sido clasificados como cancerígenos, porque inducen daño en el material genético. En este trabajo se determinó la genotoxicidad producida por extractos de durazno (Prunus pérsica (L.)Batsch) cultivados en el municipio de Pamplonita, Norte de Santander. El ensayo cometa fue utilizado para la evaluación de la actividad genotóxica. Para la detección de residuos de pesticidas, se usó cromatografía de gases $\mu \mathrm{ECD}$. Los resultados indican que el extracto de durazno induce lesiones en el ADN de linfocitos humanos, que varían de acuerdo a la dosis del extracto; por cromatografía, se detectaron pesticidas como endosulfan II y el Beta BHC, que pertenecen a la familia de los organoclorados. Dado que el durazno es un producto de exportación y de alto consumo en nuestra región, la ingesta de este podría convertirse en un factor de riesgo para la población.

Palabras clave. Durazno, genotoxicidad, ensayo cometa, pesticida

a Universidad de Pamplona, Pamplona, Colombia, Facultad de Ciencias Básicas, Grupo de Investigación en Biología Molecular y Genética. Universidad de Pamplona, Colombia, Facultad de Ciencias Básicas, Departamento de Química. Grupo de Investigación en Química. Universidad de Pamplona. Facultad de Ciencias Básicas. Departamento de Biología.

Autor de Correspondencia: imgelvez@unipamplona.edu.co 


\section{Introducción}

El durazno es una de las especies frutales caducifolias más populares cultivadas en las zonas templadas de todo el mundo. Su nombre científico, Prunus persica (L.) Batsch, sugiere que sería oriundo de Persia lo que, actualmente, se conoce como Irán[1]. Es la segunda especie frutal de mayor importancia después del manzano, en las rosáceas [1-3]. Es uno de los frutales comúnmente más sembrados en zonas de trópico alto, dentro de la llamada fruticultura de clima frío, debido a las ventajas comparativas que estas regiones poseen, como clima, suelos, precipitación y acumulación de horas frío [4]. La producción en Colombia, se concentra en los departamentos de Boyacá, Cundinamarca, Norte de Santander y Santander [5], en municipios principalmente ubicados entre 1.600 y $3.332 \mathrm{msnm}$ [6]. El departamento de Boyacá es el mayor productor de duraznero, con una producción de $12.00 \mathrm{t}$, un rendimiento de $14,4 \mathrm{tha}^{-1}$, en un área de siembra [5].

Norte de Santander se ha venido posicionando como un departamento con una gran vocación hacia los frutales caducifolios, destacándose la incorporación de nuevas áreas de siembra de duraznero, tendencia que se evidencia, ya que se pasó de $168 \mathrm{~h}$, reportadas en 2007, a 463ha, para el 2011, mostrando un incremento del $285 \%$ en el área; su participación en el mercado nacional es del 27,2\% [5]. El incremento en los dos últimos años, aproximadamente de 1000 a 1500 hectáreas puede posicionar al departamento norte de Santander en el primer lugar en el país, no solamente por área sembrada sino también por productividad por planta [7-8].

Los pesticidas son considerados como uno de los principales factores de contaminación que intervienen en el medio ambiente y el mundo de hoy[9]. Los pesticidas contribuyen a la contaminación ambiental por medio de productos degradados en aire, suelo, agua y alimentos; este contacto a largo plazo puede inducir daño en las poblaciones perturbando órganos, tejidos, sistemas entre otros[10]. Un pesticida es cualquier sustancia o mezcla de sustancias destinadas a prevenir, destruir, repeler o mitigar cualquier tipo de plagas (insectos, ácaros, nematodos, malezas, ratas, y etc.).Se pueden clasificar en insecticidas, herbicidas, fungicidas, y varias otras sustancias[11]. Estas sustancias químicas se encuentran diseñadas para ser tóxicas con las plagas y vectores de enfermedades. Contienen más de 1.000 ingredientes activos que son altamente comercializados[9] Según describe[9]. Aunque los pesticidas han beneficiado en gran medida la vida humana a través de la mejora de los productos agrícolas y el control infeccioso de enfermedades, su uso extendido y exagerado a su vez ha afectado la salud humana. Los pesticidas carbamatos, organofosfatos y pesticidas organoclorados son ampliamente aplicados a los cultivos de frutas y hortalizas en todo el mundo[12]. El uso de estos productos químicos, especialmente organoclorados en ocasiones ha estado acompañado por los riesgos para la salud humana y el medio ambiente debido a su potencial tóxico, alta persistencia, bioconcentración, y, en particular, su toxicidad no específica[13]. A pesar de que el uso de ciertos plaguicidas organoclorados en la agricultura está prohibido en muchos países, estos compuestos han sido detectados en el medio ambiente debido a su persistencia en todo el mundo. Estudios como el realizado por[14-15] demuestra que LambdaCyhalothrin, componente activo de Karate Zeon (insecticida piretroide)es utilizado altamente en la agricultura y puede causar alteración de la conciencia y convulsiones ya que afecta directamente al sistema nervioso central de los seres humanos, además de ocasionar efectos disruptores endocrinos. Otras investigaciones[16], identifican una potencial citotoxicidad y genotoxicidad in vitro de metomilo(SMetil-N-[(metilcarbamoil)oxi] tioacetamidato), componente activo del insecticida y acaricida Lannate. A sí mismo en estudios realizados por[1719] nos muestran una considerable genotoxicidad de metomilo en linfocitos humanos, induciendo aberraciones cromosómicas y micronúcleos dependientes de la dosis. Residuos de plaguicidas pueden ser encontrados en frutas y verduras y se han convertido en un importante problema de salud pública, probablemente debido al corto intervalo entre las cosechas y el tiempo transcurrido al ser llevados a los mercados y al ser consumidos en crudo[20]. Se encuentra amplia evidencia en donde muchos pesticidas están asociados con la capacidad de generar daño a nivel del material genético por ejemplo rupturas en el ADN, aductos en el ADN, aberraciones cromosómicas e intercambio de cromátidas hermanas[21-24]. Cada vez hay más pruebas de la relación de la exposición de pesticidas con la incidencia de enfermedades crónicas humanas, pues son consideradas como la principal causa de mortalidad en el nuevo mundo, lo que representa más del $60 \%$ de todas las muertes[9]. La exposición a los residuos de plaguicidas a través de la dieta se supone que es cinco órdenes de magnitud mayor que otras vías de exposición, como el agua potable[25] y el aire. Aunque la exposición a plaguicidas puede ocurrir a través de diferentes vías, como la inhalación, 
la exposición cutánea y la ingesta alimentaria y no alimentaria, el consumo de alimentos ha sido reconocido como la ruta principal de exposición a residuos de plaguicidas para los consumidores que no trabajan con pesticidas[25].

El abuso indiscriminado en la utilización de pesticidas por parte de los agricultores superando las dosis requeridas para el control de plagas ya sea por cultura, para evitar pérdidas en la producción, aumentar la productividad e intentar reducir costos; posiblemente ocasionan que queden residuos en partes de la planta y en el fruto, los cuales llegan de forma directa a los consumidores. Según reportes de los cultivadores de la región, los productos que más usan son: el funlate score, karate, sunfire, vertimek, lannate, fipronil, microthiol, daconil, derosal, forum, manzate, finale, baycor, difenoconasol, opera, tilt, azimut, nilo.(muchos de los cuales se ha demostrado tener efectos adversos en la salud y ocasionar daño genotóxico1[16-20]) Considerando que el durazno es un fruto ampliamente producido y comercializado en el ámbito local, nacional e internacional, se hace necesario realizar estudios que nos indiquen presencia o ausencia de residuos de pesticidas, los cuales pueden llegar a generar un efecto genotóxico y cancerígeno sobre los consumidores. Es por este motivo que se realizará la evaluación genotóxica, así como la identificación de residuos de pesticidas, para lograr determinar si existe una relación entre el consumo de alimentos con residuos de pesticidas y la inducción de genotoxicidad en células humanas.

\section{Materiales y Métodos}

\section{Área de estudio}

La muestra de durazno fue tomada en un cultivo localizado en el municipio de Pamplonita, el cual está ubicado en la Región Sur-Occidental del Departamento Norte de Santander, junto con los Municipios de Pamplona, Mutíscua, Silos, Chitagá y Cácota. $72^{\circ}$ 39' al oeste del meridiano de Greenwich (longitud) y a $7^{\circ} 26^{\prime}$ al norte del paralelo ecuatorial (latitud); Altitud (metros sobre el nivel del mar): 1.750 Metros. Temperatura media: media $10{ }^{\circ} \mathrm{C}$, en las zonas más altas, y de $22^{\circ} \mathrm{C}$ en las más bajas.

\section{Toma de la muestra}

Se realizaron dos (2) muestreos justo en el momento en el que son colectados para ser llevados al mercado. Tomando en total $1 \mathrm{~kg}$ de durazno, luego se guardó en cajas o termos de icopor para evitar cualquier tipo de contaminación y posteriormente almacenado a bajas temperaturas hasta el momento de su procesamiento.

\section{Obtención y preparación del extracto}

Se maceró $120 \mathrm{~g}$ de durazno durante 15 minutos hasta obtener el jugo, luego se adicionó $30 \mathrm{~mL}$ de acetona, posteriormente se centrifuga a $3500 \mathrm{rpm}$ durante 20 minutos después de los cuales se retiró y se almaceno el sobrenadante. Este procedimiento se repite 5 veces. Para la concentración del material presente en el extracto, el sobrenadante recolectado se pasó a través de una columna que contenía amberlita XAD-2 (15g) a una velocidad de 15 $\mathrm{mL} / \mathrm{min}$; el material retenido por la amberlita fue eluido con $100 \mathrm{~mL}$ de diclorometano. Después de obtenido el extracto, se concentró en un evaporador rotatorio de vacío a baja presión (Heidolph modelo Laborota 400-1), hasta la sequedad, seguidamente se cuantificó el extracto seco equivalente a los 120 gramos iniciales.

El extracto obtenido se dividió en dos partes, la primera parte para los análisis genotoxicos el cual se diluyo en $3 \mathrm{ml}$ de dimetil sulfóxido al $1 \%$ y la parte restante para el análisis cromatográfico.

Extracción de linfocitos: Para los experimentos de genotoxicidad, se usaron linfocitos de sangre periférica, que se extrajeron de una persona joven y sana. Los linfocitos se separaron de la sangre total, usando un gradiente de ficollhipaque. Seguidamente, se determinó la viabilidad, la cual, siempre se mantuvo por encima del $90 \%$.

\section{Detección de daño del ADN por el Ensayo Cometa}

Se trataron alrededor de 40.000 células o linfocitos con tres dosis $(100 \mu \mathrm{g}, 200 \mu \mathrm{g}$ y $300 \mu \mathrm{g})$ de extractos de durazno, se incubaron por un periodo de 1 hora a $37^{\circ} \mathrm{C}$, las placas se sumergieron $1 \mathrm{~h}$ en solución de lisis. Las placas se lavaron con PBS y se colocaron en una unidad de electroforesis horizontal con un buffer $\mathrm{pH}>13$ y se incubó por 30 minutos, luego se corrió a $25 \mathrm{~V}$ y $300 \mathrm{~mA}$ por 30 minutos. Después de la electroforesis, las placas fueron lavadas con un buffer neutralizante por 10 , luego se tiñeron con $50 \mu \mathrm{lde}$ Bromuro de etidio $(0.02 \mathrm{mg} / \mathrm{mL})$. Las observaciones se realizaron en un microscopio de fluorescencia (Olimpus Cx41) equipado con filtro de 515-560 nm y un filtro de barrera de $590 \mathrm{~nm}$. Para estos resultados se hicieron tres experimentos por cada tratamiento y en cada uno se contaron 100 células. Como control negativo se utilizó, el DMSO al 1\%, que fue el solvente de las muestras. La ocurrencia de daño en 
el ADN se determinó mediante el uso del software (Tritek Comet ScoreTM freeware v1.5) basado en las siguientes mediciones: longitud total del cometa, área del cometa $\left(\mu \mathrm{m}^{2}\right)$, diámetro de la cabeza $(\mu \mathrm{m})$, $\%$ DNA en cabeza, longitud de la cola $\mu \mathrm{m}, \% \mathrm{DNA}$ en cola..

\section{Identificación de pesticidas en extractos de duraznos por Cromatografía de Gases $\mu$ ECD}

Para identificar residuos de pesticidas presentes en extractos de durazno extraídas con diclorometano y acetona se utilizó un equipo de cromatografía de gases marca Agilent Technologies 6890A Plus Series II Hewlet-Packard Plus con detector $\mu \mathrm{ECD}$ (microcaptura electrones). La columna es Restek Rtx-5 $30 \mathrm{~m}$ de longitud, $0.32 \mathrm{~mm}$ de diámetro, $0.25 \mu \mathrm{m}$ de diámetro interno (Crossbond $5 \%$ diphenyl 95\% dimethylpolysiloxane). Para la identificación de los pesticidas, se utilizó patrones puros, que se inyectaron individualmente. La identificación cualitativa de los pesticidas presentes en el extracto se realizó de acuerdo a las siguientes condiciones: detector $\mu \mathrm{ECD}$ a $320^{\circ} \mathrm{C}$ Mezcla $(\mathrm{mL} / \mathrm{min})$ : Aire 400 - H2 $30-\mathrm{N} 2$ 45. Se inyectó $1 \mu 1$, modo splitless a $320 \mathrm{oC}$. Temperatura inicial $45^{\circ} \mathrm{C}$ por $0.8 \mathrm{~min}$ y se incrementó de la siguiente manera: $45^{\circ} \mathrm{C} / \mathrm{min}$ hasta $200^{\circ} \mathrm{C}, 2,50^{\circ} \mathrm{C} / \mathrm{min}$ hasta $225^{\circ} \mathrm{C}, 3^{\circ} \mathrm{C} / \mathrm{min}$ hasta $266^{\circ} \mathrm{C}, 5^{\circ} \mathrm{C} / \mathrm{min}$ hasta $300^{\circ} \mathrm{C}, 10^{\circ} \mathrm{C} / \mathrm{min}$ hasta $320^{\circ} \mathrm{C}$ durante 4,50min.Tiempo de análisis por muestra $41.21 \mathrm{~min}$. Gas de arrastre Helio, flujo $20 \mathrm{~mL} / \mathrm{min}$. Temperatura del inyector $250{ }^{\circ} \mathrm{C}$.

\section{Analisis Estadistico}

Se realizó un análisis de varianza (ANOVA) utilizando el programa estadístico SPSS versión 19; se realizó la prueba de homogeneidad de varianzas.

\section{Resultados}

Se estima el porcentaje de viabilidad celular de los linfocitos utilizando el método de exclusión de azul tripano, el cual siempre se mantuvo por encima del $90 \%$.

En la tabla 1 se muestra la genotoxicidad en linfocitos humanos expuestos a extractos de durazno, detectado por el ensayo cometa. Los resultados indican que existe un efecto genotóxico (longitud del cometa), dependiente de la dosis utilizada con un $\mathrm{P}<0.05$ según la prueba Tukey. Se observa que a medida que se aumenta la dosis los valores analizados aumentan comparados con el control negativo.

Como se puede observar en la Tabla 1 y Figura 1, la longitud total del cometa de las células tratadas con DMSO 1\%, muestran un daño espontáneo, llegando a un promedio de $51.4 \mu \mathrm{m}$ de longitud; de igual manera, las células tratadas con $\mathrm{H}_{2} \mathrm{O}_{2} 100$ $\mu \mathrm{M}$ llegan a un valor de $94.2 \mu \mathrm{m}$, casi superando el doble en longitud al control negativo. Como se puede observar Tabla 1 y en la Figura 1, la dosis de $100 \mu \mathrm{g}$ muestra un valor de $62.4 \mu \mathrm{m}$ que al compararlo con el control negativo no muestra una diferencia estadísticamente significativa $\mathrm{P}>0.05$. Si observamos la dosis de $200 \mu \mathrm{g}$ la cual supera 1.5 veces la respuesta del control negativo, nos damos cuenta que se genera incremento moderado del daño genético de las células expuestas al extracto. De igual manera la dosis de $300 \mu$ g supera 2.6 veces la respuesta del control negativo, indicando que a esta concentración se genera un daño estadísticamente significativo.

Tabla 1. Daño inducido en el ADN de linfocitos humanos por diferentes dosis de extracto de durazno cultivado en el municipio de Pamplonita N/S.

\begin{tabular}{|c|c|c|c|c|c|c|c|}
\hline & $\begin{array}{c}\text { Longitud } \\
\text { cometa }(\mu \mathrm{m})\end{array}$ & $\begin{array}{c}\text { Diámetro } \\
\text { cabeza }(\mu \mathrm{m})\end{array}$ & $\begin{array}{l}\text { \%DNA } \\
\text { cabeza }\end{array}$ & $\begin{array}{c}\text { Longitud cola } \\
(\mu \mathrm{m})\end{array}$ & \%DNA cola & $\begin{array}{c}\text { Momento de } \\
\text { cola }\end{array}$ & Momento Olive \\
\hline DMSO $1 \%$ & 51.4 & 45.3 & 97.8 & 6.6 & 2.2 & 0.2 & 0.3 \\
\hline$H 2 O 2100 \mu M$ & 94.2 & 36.5 & 94.8 & 51.7 & 5.2 & 2.3 & 1.5 \\
\hline $100 \mu g$ & 62.4 & 38.4 & 96.9 & 24.1 & 2.9 & 0.6 & 0.5 \\
\hline $200 \mu g$ & 79.1 & 35.8 & 94.4 & 43.3 & 4.2 & 1.6 & 1.0 \\
\hline $300 \mu \mathrm{g}$ & 134.4 & 35.2 & 91.4 & 100.4 & 6.4 & 5.0 & 2.8 \\
\hline
\end{tabular}

Como control negativo se utilizó DMSO 1\%. Como control positivo se utilizó peróxido de hidrogeno $\mathrm{H}_{2} \mathrm{O}_{2} 100 \mu \mathrm{M}$ control, Diferentes dosis de extracto de durazno $100 \mu \mathrm{g}, 200 \mu \mathrm{g}, 300 \mu \mathrm{g}$ - 


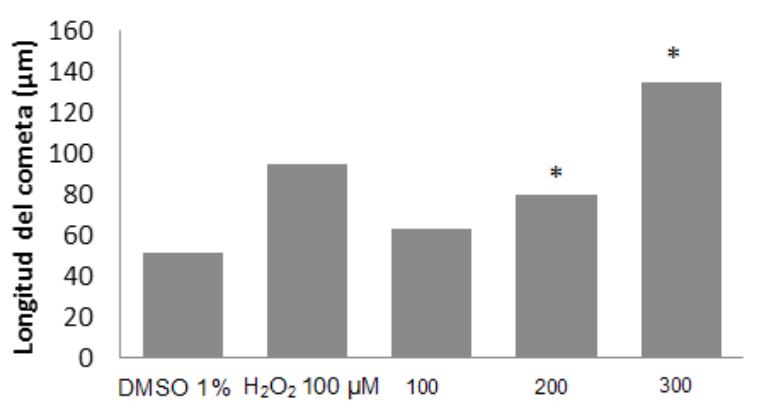

Dosis de extracto de durazno en $\mu \mathrm{g}$

Figura 1. Daño en el ADN de linfocitos humanos inducido por diferentes dosis de extracto de durazno. Los valores mostrados corresponden a la media de 300 cometas por dosis. Como control negativo se utilizó DMSO 1\%. Como control positivo se utilizó peróxido de hidrogeno $\mathrm{H}_{2} \mathrm{O}_{2} 100$ $\mu M$. *Diferencia estadísticamente significativa respecto al control negativo, $P<0.05$.

Se evidencia en la Tabla 1, que a medida que se incrementa la concentración de extracto en cada dosis disminuye el diámetro de la cabeza $(\mu \mathrm{m})$ progresivamente. en comparación con el control negativo (DMSO 1\%, 45.3 $\mu \mathrm{m}$ ) En la dosis de 100 $\mu \mathrm{g}$ disminuye su diámetro en un $15.24 \%$, en la dosis de $200 \mu \mathrm{g}$ en un $20.98 \%$ y en la dosis de $300 \mu \mathrm{g}$ en un $22.3 \%$, así mismo se observan que los rangos de porcentaje de ADN en cabeza tiene la misma tendencia a disminuir a medida que se aumenta la concentración de cada dosis de extracto de durazno, en el control negativo (DMSO 1\%) observamos un porcentaje de 97.8 de ADN en cabeza, en la dosis de $100 \mu \mathrm{g} 96.9 \%$, en la dosis de $200 \mu \mathrm{g} 94.4 \%$, y en la dosis de $300 \mu \mathrm{g} 91.4 \%$, estos datos varían inversamente proporcional a la concentración de cada dosis; se las dosis aumentan, disminuye tanto el diámetro de la cabeza como su porcentaje de ADN.

La longitud de cola $(\mu \mathrm{m})$ como el porcentaje de $\mathrm{ADN}$ en cola se ven directamente relacionadas ya que a medida que la longitud de cola del cometa aumenta, aumenta el porcentaje de ADN en la misma. Se observa para el control negativo valores en longitud de cola de $6.6 \mu \mathrm{m}$ y $2.2 \%$ de porcentaje de ADN. Las dosis evaluadas nos muestran que para 100ug se da un aumento en 3.6 veces la longitud de cola y 1.3 veces \% de ADN. La dosis de $200 \mu \mathrm{g}$ nos muestra un aumento de 6.5 veces en la longitud de cola y 1.9 veces \% de ADN. De igual manera, la dosis de $300 \mu \mathrm{g}$ nos muestra un aumento de 15.2 veces en la longitud de cola y 2.9 veces $\%$ de ADN.

En el momento Olive y momento cola se observan cambios dependientes de la dosis en los linfocitos tratados. Se obtiene un valor de 0.3 en el control negativo. EL valor más bajo (0.5), fue mostrado en la dosis de $100 \mu \mathrm{g}$ y el valor más alto (2.8) en la dosis de $300 \mu \mathrm{g}, 9.3$ veces más que el control negativo.

En la Figura 3 se observa el cromatograma del compuesto puro endosulfan II perteneciente a la familia de los organoclorados, detectado a los 33.194 minutos. Así mismo en la Figura 4 se observa el cromatograma del compuesto puro del pesticida Beta BHC, detectado a los 13.353 minutos.

La Figura 5 corresponde al cromatograma del extracto de durazno se observan dos picos representativos, el primero a los $14.761 \mathrm{~min}$ y el segundo a los 33.421 minutos.
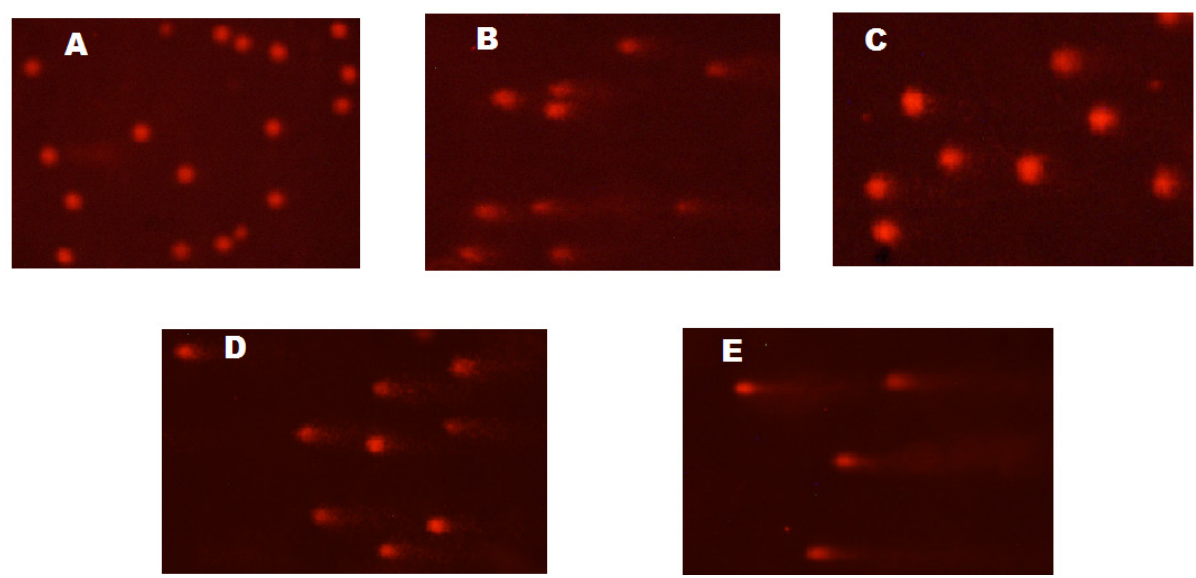

Figura 2. Imágenes del daño inducido en linfocitos humanos por muestras de extracto de durazno, cultivados en Pamplonita, Norte de Santander. A: DMSO 1\%, B: $\mathrm{H}_{2} \mathrm{O}_{2} 100 \mu \mathrm{M}, \mathrm{C}: 100$ $\mu g, D: 200 \mu$ y $E: 300 \mu g$ 


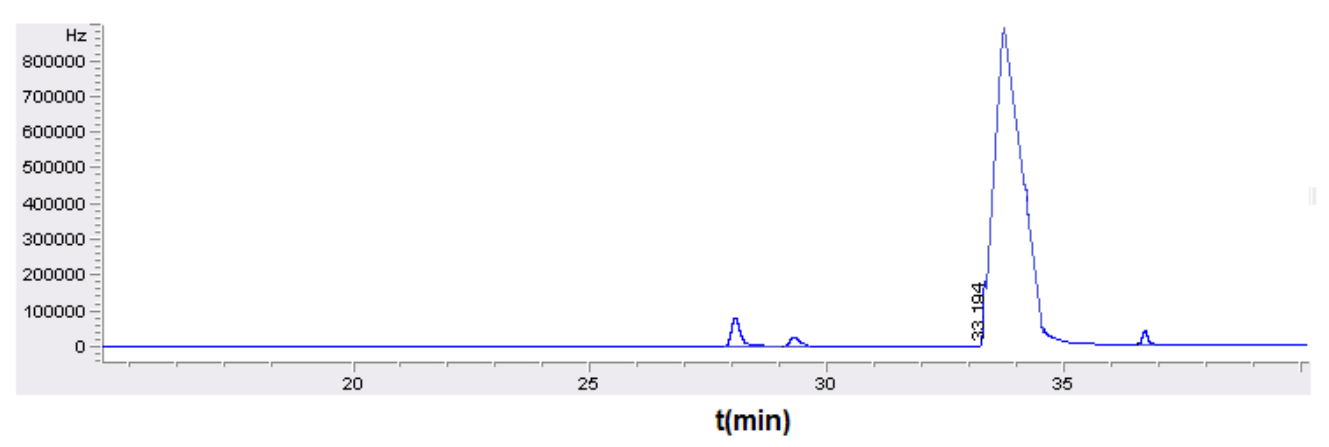

File Information

\begin{tabular}{|} 
File Information \\
\begin{tabular}{|r|l|}
\hline GC-File & SIG1000007.D \\
\hline File Path & C:CCHEM32\1\DATA\2016-01-23\} $\\
{\hline \text { Date }} &{\text { 15Jun-16, 11:50:09 }} \\
{\hline \text { Sample }} &{\text { Patron Endosulfan II }} \\
{\hline}$
\end{tabular}
\end{tabular}

\begin{tabular}{|c|c|c|c|c|c|c|}
\hline$\#$ & Time & Area & Height & width & Area\% & Symmetry \\
\hline 46 & 31.479 & 1308.9 & 147.7 & 0.1234 & 0.029 & 0.875 \\
\hline 47 & 31.72 & 569 & 33.7 & 0.2091 & 0.013 & 0.203 \\
\hline 48 & 32.223 & 48.6 & 10.3 & 0.0608 & 0.001 & 2.64 \\
\hline 49 & 32.295 & 23.7 & 15.2 & 0.026 & 0.001 & 0.803 \\
\hline 50 & 33.194 & 3669.7 & 91.2 & 0.4776 & 0.083 & 43.123 \\
\hline 51 & 36.731 & 274172.2 & 40266.9 & 0.1094 & 6.179 & 1.066 \\
\hline 52 & 37.064 & 4754.9 & 779.3 & 0.0952 & 0.107 & 0.584 \\
\hline
\end{tabular}

Figura 3. Cromatograma patrón Pesticida Endosulfan II.

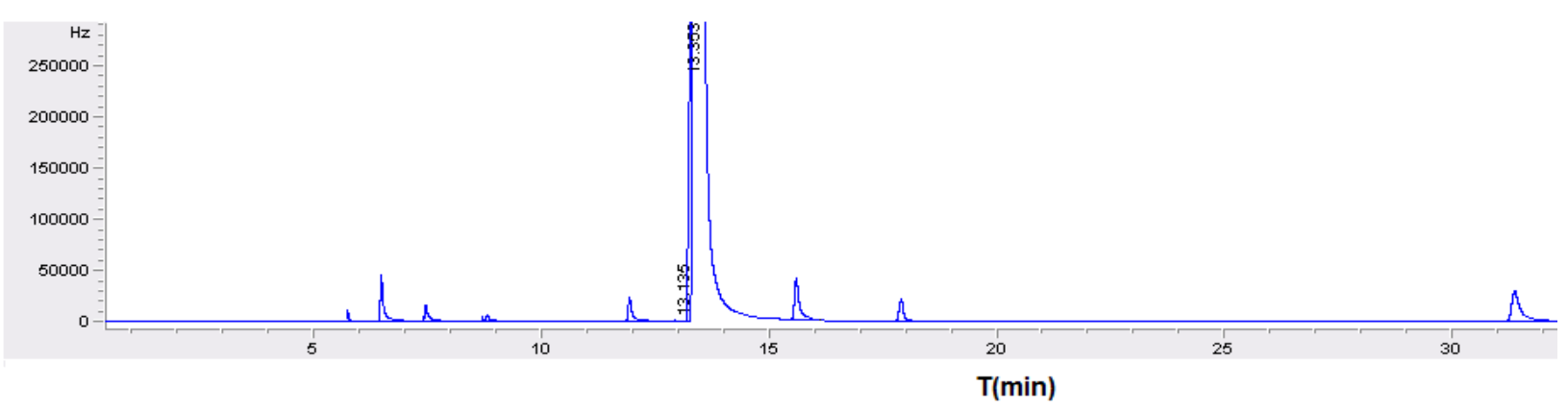

File Information

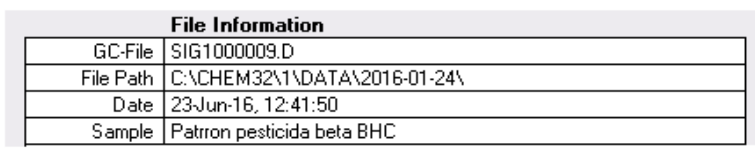

\begin{tabular}{l|c|c|c|c|c|c|}
\multicolumn{1}{|c}{ \# } & Time & Area & Height & Width & Area\% & Symmetry \\
\hline 35 & 11.213 & 8113 & 1321 & 0.0877 & 0.124 & 0.479 \\
\hline 36 & 11.697 & 71.8 & 17 & 0.0612 & 0.001 & 1.696 \\
\hline 37 & 11.917 & 125575.6 & 22719.8 & 0.0805 & 1.926 & 0.522 \\
\hline 38 & 12.237 & 10849.9 & 824.7 & 0.2193 & 0.166 & 0.27 \\
\hline 39 & 13.135 & 886.3 & 103.7 & 0.1137 & 0.014 & 2.391 \\
\hline 40 & 13.353 & 343521.3 & 272148.1 & 0.0247 & 5.269 & 0.76 \\
\hline 41 & 15.084 & 10557.4 & 1062.1 & 0.148 & 0.162 & 0.365 \\
\hline
\end{tabular}

Figura 4. Cromatograma Patrón pesticida Beta BHC.

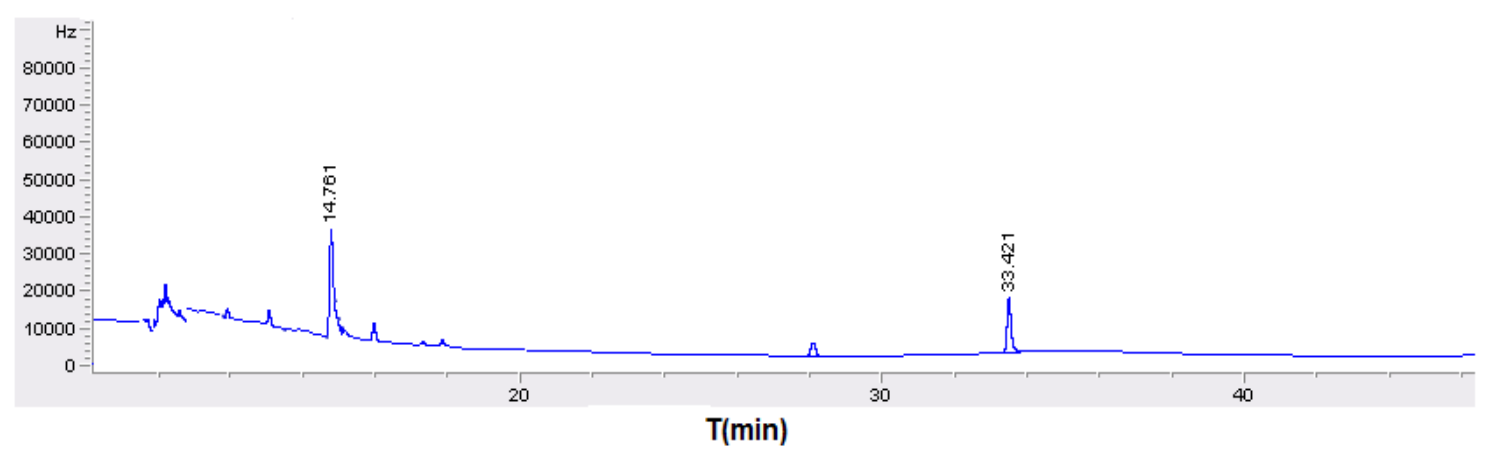

File Information

File Information
\begin{tabular}{|r|l|}
\hline GC-File & SIG1000005.D \\
\hline File Path & C:CCHEM32\1\DATA\2016-01-24\} $\\
{\hline \text { Date }} &{\text { 22Jun-16, 15:53:03 }} \\
{\hline \text { Sample }} &{\text { Extracto durazno acetona }} \\
{\hline}$
\end{tabular}

\begin{tabular}{|c|c|c|c|c|c|c|}
\hline$\#$ & Time & Area & Height & Width & Area\% & Symmetry \\
\hline 21 & 10.04 & 1004762.2 & 20289.3 & 0.8254 & 6.790 & 0.256 \\
\hline 22 & 10.948 & 614077.6 & 12478.7 & 0.8202 & 4.150 & $1.88 \mathrm{E}-2$ \\
\hline 23 & 11.898 & 446455.8 & 12446 & 0.5979 & 3.017 & 0.144 \\
\hline 24 & 13.052 & 453709.7 & 11823.5 & 0.6396 & 3.066 & 1.24 \\
\hline 25 & 13.559 & 395926.7 & 6971.5 & 0.807 & 2.676 & $7.74 \mathrm{E}-2$ \\
\hline 26 & 14.761 & 369057.4 & 33171.8 & 0.1854 & 2.494 & 0.502 \\
\hline 27 & 15.143 & 181141.5 & 5806.4 & 0.5199 & 1.224 & 0.139 \\
\hline
\end{tabular}

Figura 5. Cromatograma correspondiente al extracto de durazno. 


\section{Analisis de Resultados.}

En los resultados obtenidos en cada una de las dosis de extracto de durazno y comparados con el control negativo, se notó una tendencia creciente de daño genotóxico según el aumento de la concentración de las mismas, llevando a un incremento de las lesiones primarias sobre el $\mathrm{ADN}$, lo cual, está directamente relacionado con el aumento en las alteraciones genéticas celulares. Resultados similares han sido reportado por[26-9], quienes encontraron que los pesticidas inducen daño oxidativo en el ADN a través de especies reactivas de oxígeno. Estas especies reactivas de oxígeno (ROS) están implicadas en la toxicidad de diversos plaguicidas incluidos los plaguicidas organofosforados. Se sabe que ROS induce varios tipos de lesiones en el ADN incluidas rupturas simples y dobles, sitios lábiles alcalinos y oxidación de purinas y pirimidinas que son detectados fácilmente por el ensayo de cometa[27-29]. En estudios realizados por[20-29], observaron que las dosis en la que se induce mayor frecuencia de células con daño en el $\mathrm{ADN}$, también muestran mayor longitud de migración del ADN. Esto podría indicar que los genotoxicos que producen más daño en el ADN, también afectan más número de células. Otros estudios demuestran que el efecto que produce alteraciones en el material genético es probablemente causado, además, por la presencia de metales, incluyendo el hierro, manganeso, cobre, zinc y arsénico, debido a su alta actividad mutagénica y genotoxica[30]. Se ha demostrado que los iones metálicos presentes en algunos pesticidas pueden interferir con la reparación del ADN y producir especies reactivas de oxigeno (ROS), que conducen a daño oxidativo[31]. Hay evidencia que demuestra que el exceso de metales como el cobre puede inducir estrés oxidativo que puede dar lugar a ataques de radicales libre, vía reacciones Fenton[32]. Aunque el cobre es un metal bioesencial para el funcionamiento normal de las células, también puede catalizar la formación de radicales libres de hidroxilo en las reacciones de Haber-Weiss catalizada por metales Fenton, lo que resulta en daño oxidativo del ADN[33]. Existen evidencias que han sugerido que el arsénico es causante de enfermedades como cáncer de vejiga, pulmón, hígado y piel, así como trastornos del sistema cardiovascular y nervioso[34]. Estudios de[35-36], describen el arsénico como causante de intercambio de cromátidas hermanas, aberraciones cromosómicas y aneuploidías. Además, se ha encontrado que causa la inhibición del crecimiento celular, bloqueo del ciclo celular en la mitosis induciendo apoptosis[37-38].

De acuerdo a los reportes en literatura y a los encontrados en este estudio, podríamos relacionar la genotixicidad encontrada en este ensayo con la presencia de residuos de pesticidas en el fruto del durazno, dado que cuando se realizó la identificación a través de cromatografía de Gases $\mu \mathrm{ECD}$, se evidenció la presencia del pesticida de la familia de los organoclorados como el endosulfan II detectado a los 33.421 min (Figura 5), el cual coincide con el cromatograma del patrón puro observado a los 33.194 minutos (Figura 3). También se observó a los 14.761 min (Figura 5) un pico, que corresponde al compuesto puro Beta BHC, que se detectado a los 13.53 min (Figura 4). Es de resaltar, que aunque estos compuestos no se reportan por parte de los agricultores, se evidencia su uso. Estudios científicos por[39] caracterizan a endosulfán como un agente carcinógeno potencial en humanos asi como genotóxico en bacterias, células humanas y en células de ratones, además de ser promotor de tumores y agente mutagénico[40]

\section{Conclusiones}

Podemos concluir que extractos de durazno cultivados en el municipio de Pamplonita y que están siendo comercializado en la provincia de pamplona inducen actividad genotóxica en linfocitos humanos, lo cual podría constituir un factor de riesgo para la población expuesta, teniendo en cuenta la relación que existe entre daño genotóxico y aparición de enfermedades tales como el cáncer. Se deben plantear alternativas para disminuir el uso indiscriminado de plaguicidas organoclorados ya que son considerados como uno de los principales problemas ambientales $\mathrm{y}$ de salud humana en el mundo.

\section{Referencias}

[1] Cárdenas J, Fischer G,. Clasificación botánica y morfología de manzano, peral, duraznero y ciruelo. Situación actual, sistemas de cultivo y plan de desarrollo. Soc. Col. Cienc. Hort. 2013; 24-25.

[2] Bardenes ML, Lorente M, Martinez J, y Yacer G. Variedades de melocotón y Nectarina Temprana. Universidad Politecnica de Valencia. Valencia . España.1999.

[3] United State Department of Agriculture USDA-. Natural Resources Conservation Service, Plant Database. 2013.

[4] Puentes G, Rodríguez LF, Bermúdez L. Análisis de grupo de las empresas productoras de frutales caducifolios del departamento de Boyacá. Agr. Col. 2008; 26 (1): 146-154. 
[5] Ministerio de agricultura y desarrollo rural -MADR-. Anuario estadístico de frutas y hortalizas. 2012.

[6] Carranza C, Miranda D. Zonificación actual de los sistemas de producción de frutales caducifolios en Colombia. Situación actual, sistemas de cultivo y plan de desarrollo. Soc. Col. Cienc. Hort. 2013; 67-86.

[7] Pinzón EH, Cruz Morillo, Fischer G. Aspectos fisiológicos del duraznero (Prunus persica [L.] Batsch) en el trópico alto. Una revisión. Rev. U.D.C.A Act. \& Div. Cient. 2014; 17 (2): 401411.

[8] Peñaranda Cáceres Guillermo. análisis de costos de la producción de durazno (prunus pérsica) en la provincia de Pamplona, Norte de Santander.Face. 2012; 145-162.

[9] Mostafalou Sara, Mohammad Abdollahi. Pesticides and human chronic diseases: Evidences, mechanisms, and perspectives. Toxicology and Applied Pharmacology. 2013; 268: 157-177.

[10] Collotta M, Bertazzi PA,Bollati V, Epigenetics and pesticides. Toxicology. 2013; 1-7.

[11] Environmental Protection Agency, EPA EEUU. What is a pesticide?. 2009. http://www. epa.gov/pesticides

[12] Zhang W, Jiang F, Ou J. Global pesticide consumption and pollution : with China as a focus Proc. Int. Acad. Ecol. Environ. Sci. 2011; 125-144.

[13] Bempah CK, Donkor AK. Pesticide residues in fruits at the market level in Accra Metropolis, Ghana, a preliminary study Environ. Monit. Assessment. 2011; 175: 551-561.

[14] Haibing Li, Yuling Li, Jing Cheng. Molecularly Imprinted Silica Nanospheres Embedded CdSe Quantum Dots for Highly Selective and Sensitive Optosensing of Pyrethroids. Central China Normal University, China. 2010; 22: 2451-2457

[15] Oudou HC, Alonso RM, Bruun Hansen HC. Voltammetric behaviour of the synthetic pyrethroid lambda-cyhalothrin and its determination in soil and well water. Analytica Chimica Acta. 2004; 523: 69-74.

[16] Xiang Guanggang, Li Diqiu, Yuan Jianzhong, Guan Jingmin, Zhai Huifeng, Shi Mingan, Tao Liming. Carbamate insecticide methomyl confers cytotoxicity through DNA damage induction. Food and Chemical toxicology. 2013; 53: 352-358.

[17] Bolognesi C, Peluso M, Degan P, Rabboni R, Munnia A, Abbondandolo A. Genotoxic effects of the carbamate insecticide, methyomyl. II. In vivo studies with pure compound and the technical formulation, "Lannate 25"Environmental and Molecular Mutagenesis. 1994; 235-242

[18] Falck GC, Hirvonen A, Scarpato R, Saarikoski ST, Migliore L, Norppa H. Micronuclei in blood lymphocytes and genetic polymorphism for GSTM1, GSTT1 and NAT2 in pesticideexposed greenhouse workers Mutation Research. 1991; 441: 225-237

[19] Sun XY, Jin YT, Wu B, Wang WQ, Pang XL, Wang J. Study on genotoxicity of aldicarb and methomyl. Huan Jing Ke Xue.2010; 31: 29732980

[20] Pabuena Duban E, Ortiz Isabel C , López Juan, Orozco Luz J., Quijano Parra Alfonso, Pardo Enrique, Meléndez Iván. Actividad genotóxica inducida por extracto de fresa fumigada con pesticidas en Pamplona, Norte de Santander, Colombia. Universidad, Ciencia y Tecnología. 2015; 19 : 76.

[21] Lander BF, Knudsen LE, Gamborg MO, Jarventaus H, \& Norppa H. Chromosome aberrations in pesticide-exposed greenhouse workers.. Scand J Work Environ Health. 2000; 26 (5): 436-442.

[22] ZeljezicD, \& Garaj-Vrhovac V. Sisterchromatid exchange and proliferative rate index in the longitudinal risk assessment of occupational exposure to pesticides. Chemosphere. 2002; 46 (2): 295-303.

[23] Grove P, Danadevi RK, Mahboob M, Rozati R, Banu BS, \& Rahman MF. Evaluation of genetic damage in workers employed in pesticide production utilizing the Comet assay. Mutagenesis. 2003; 18 (2): 201-205.

[24] Lee WJ, Blair A, Hoppin JA, Lubin JH, Rusiecki JA, Sandler DP, Alavanja MC. Cancer incidence among pesticide applicators exposed to chlorpyrifos in the Agricultural Health Study. J Natl Cancer Inst. 2004; 96 (23): 1781-1789.

[25] Juraske R, Mutel CL, Stoessel F, Hellweg $\mathrm{S}$. Life cycle human toxicity assessment of pesticides: comparing fruit and vegetable diets in switzerland and the united states Chemosphere. 2009; 77 (7): 939-945.

[26] Idris S, Ambali S, Ayo J. Cytotoxicity of chlorpyrifos and cypermethrin: the ameliorative effects of antioxidants. Afr J Biotechnol. 2012; 11 (99): 16461-16467.

[27] Collins AR, Dobson VL, Dusinska M, Kennedy G, Stetina R. The comet assay: what can it really tell us.Mutat. $1997 ; 375: 183-193$. 
[28] Collins AR, Duthie SJ, Dobson VL. Direct enzymatic detection of endogenous oxidative base damage in human lymphocyte DNA Carcinogenesis. 1993; $14:$ 1733-1735.

[29] Meléndez Gélvez I, Martínez Montañez ML, Quijano Parra A. Actividad mutagénica y genotóxica en el material particulado fracción respirable MP2,5 en Pamplona, Norte de Santander, Colombia. Iatreia .2012; 25 (4): 347-356.

[30] Vargas V, Migliavacca S, Melo A, Horn R. Genotoxicity assessment in aquatic environments under the influence of heavy metals and organic contaminants. Mut.2001; 490: 141-158.

[31] Bull S, Fletcher K, Boobis AR, Battershill $\mathrm{JM}$, Evidence for genotoxicity of pesticides in pesticide applicators: a review. Mutagenesis, 2006; 21 (2): 93-103.

[32] Bertoncini CR, Meneghini R. DNA strand breaks produced by oxidative stress in mammalian cells exhibit 3 '-phosphoglycolate termini Nucleic Acids. 1995; 23: 2995-3002.

[33] Shrivastava R, Upreti RK, Seth PK, Chaturvedi UC. Effects of chromium on the immune system FEMS Immunol. Med. Microbiol. 2002; 34 (1): $1-7$.

[34] Nesnow S, Roop BC, Lambert G, Kadiiska M, Mason RP, Cullen W.R, Mass MJ. DNA damage induced by methylated trivalent arsenicals is mediated by reactive oxygen species. Chemical Research Toxicology. 2002; 15: 1627-1634

[35] Basu A, Ghosh P, Das JK, Banerjee A, Ray
K, Giri AK. Micronuclei as biomarkers of carcinogen exposure in populations exposed to arsenic through drinking water in West Bengal, India: a comparative study in three cell types. Cancer Epidemiology Biomarkers and Prevention. 2004; 13: 820-827

[36] Mahata J, Basu A, Ghoshal S, Sarkar JN, Roy AK, Poddar G, Nandy AK, Banerjee A, Ray K, Natarajan AT, Nilsson R, Giri AK. Chromosomal aberrations and sister chromatid exchanges in individuals exposed to arsenic through drinking water in West Bengal, India. Mutation Research. 2003; 534: 133-143

[37] Ling YH, Jiang JD, Holland JF, Perez Soler R. Arsenic trioxide polymerization of microtubules and mitotic arrest before apoptosis in human tumor cell lines Molecular Pharmacology. 2002; 62: 529-538

[38] Nesnow S, Roop BC, Lambert G, Kadiiska M, Mason RP, Cullen WR, Mass MJ. DNA damage induced by methylated trivalent arsenicals is mediated by reactive oxygen species. Chemical Research Toxicology. 2002; 15: 1627-1634

[39] Antherieu S, Ledirac N, Luzy AP, Lenormand P, Caron JC, Rahmani R. Endosulfan decreases cell growth and apoptosis in human $\mathrm{HaCaT}$ keratinocytes: Partial ROS-dependent ERK1/2 mechanism. J Cell Physiol. 2007; 213: 177-86.

[40] Chaudhuri K, Selvaraj S, Pal AK. Studies on the genotoxicity of endosulfan in bacterial systems.1999. Mutat Res 439 (1): 63-7. 
